Original Research Paper

\title{
A General Strategy to Enhance Upconversion luminescence in Rare-Earth-Ion-Doped Oxide Nanocrystals
}

\author{
${ }^{1,2}$ Guanying Chen and ${ }^{1}$ Lei Xu \\ ${ }^{1}$ School of Chemical Engineering and Technology, Harbin Institute of Technology, Harbin 150001, China \\ ${ }^{2}$ Institute for Lasers, Photonics and Biophotonics, The State University of New York at Buffalo, Buffalo, NY 14260, USA
}

\author{
Article history \\ Received: 02-02-2016 \\ Revised: 04-02-2016 \\ Accepted: 06-02-2016 \\ Corresponding Author: \\ Guanying Chen \\ School of Chemical \\ Engineering and Technology, \\ Harbin Institute of Technology, \\ Harbin 150001, China \\ Email: chenguanying@hit.edu.cn
}

\section{Introduction}

Inorganic Upconversion (UC) nanocrystals doped with rare-earth ions have garnered significant attentions in literature due to their potential use in color displays (Shalav et al., 2005), solar cells (Liu et al., 2004), DNA detection (Wang and Li, 2006), background-free fluorescence imaging (Lim et al., 2006) and deep tumor treatment via Photodynamic Therapy (PDT) (Chen et al., 2014), etc. Such endeavors gain a lot from UC nanocrystals' unique capability that they can upconvert the absorbed, usually infrared and Near Infrared (NIR) light, into visible and ultraviolet radiations via the embedded rare-earth ions (Auzel, 2004; Vetrone et al., 2003). Unfortunately, these nanocrystals display a serious shortcoming, since their luminescent efficiency is inadequate to meet the requirements of many practical applications (Suyver et al., 2005; Sivakumar et al., 2007). Among inorganic nanocrystals, oxide nanocrystals exhibit higher mechanical, thermal and chemical stabilities and constitute a distinguished endeavor for biomedical and photonic applications. The realization of efficient NIR to visible UC Luminescence (UCL) in the category of oxide nanocrystals will unlock a realm of new possibilities for their biomedical and photonic applications.

It is known that the main intra-4f electronic-dipole transitions of rare-earth ions are forbidden by the quantum mechanical selection rules. However, this prohibited nature can be broken by the rare-earth ions' local surrounding crystal field due to its capability to intermix the $f$ states of rare earth ions with the higher electronic configurations (Weber, 1967). We thereby propose a strategy on engineering on rare-earth ions' local environment in the host lattice to tailor their radiation parameters to increase the UCL output. The $\mathrm{Li}^{+}$ions have the smallest cationic radius in the periodic table (favorable for the movement and localization in the lattice) that makes them attractive for use in this task. The $\mathrm{Li}^{+}$ions around rare-earth ions in the lattice, particularly that occupy the interstitial cites, can impose a columbic field on rare earth ions, which thereby can modify the local environment to increase the UCL. Based on this hypothesis, we have demonstrated that the UCL from $\mathrm{Y}_{2} \mathrm{O}_{3}: \mathrm{Er}^{3+}$ nanocrystals can be significantly increased via codoping with $\mathrm{Li}^{+}$ions (Chen et al., 2008a). Bai et al. (2008) reported on a similar observation in parallel. Here, we generalize this strategy to the category of oxide nanocrystals and to the class of rare-earth ions. Measured experimental results evidenced that the UCL could be increased by orders of magnitude via doping further with $\mathrm{Li}^{+}$ions. Regarding the generalization of the proposed strategy, we took two parallel steps to justify the conclusion: (1) the demonstration of its general validity in nanocrystals of different oxide host lattice doped with a specific rare-earth ion; (2) the demonstration of its general validity for diverse rare-earth ions (codoping and tridoping) in a specific host lattice.

\section{Experimental}

Nanocrystals of $\mathrm{Y}_{2} \mathrm{O}_{3}\left(\mathrm{Gd}_{2} \mathrm{O}_{3}\right.$ or $\left.\mathrm{ZnO}\right)$ powders doped with $\mathrm{Er}^{3+}\left(\mathrm{Yb}^{3+} / \mathrm{Tm}^{3+}, \mathrm{Yb}^{3+} / \mathrm{Er}^{3+}, \mathrm{Yb}^{3+} / \mathrm{Ho}^{3+}\right.$ and 
$\left.\mathrm{Yb}^{3+} / \mathrm{Er}^{3+} / \mathrm{Tm}^{3+}\right)$ and codoped with various concentrations of $\mathrm{Li}^{+}$ion were synthesized according the following procedure: Yttrium nitrate, rare-earth nitrates $\left(\mathrm{Er}^{3+}, \mathrm{Tm}^{3+}, \mathrm{Ho}^{3+}\right.$ and $\left.\mathrm{Yb}^{3+}\right)$ and lithium nitrate, with corresponding mole ratio, were first completely dissolved in the deionized water. Subsequently, citric acid was added into the solution with a mole ratio of $(\mathrm{Y}+\mathrm{RE}+\mathrm{Li})$ to citric acid of 1:4. After complete dissolution, the $\mathrm{pH}$ of the solution was adjusted to 6.0 by addition of ammonium hydroxide. The resulting solution was dried at $120^{\circ} \mathrm{C}$ for $24 \mathrm{~h}$ until it was transformed into a black bulk, which was further calcined at $800^{\circ} \mathrm{C}$ for $2 \mathrm{~h}$ in air. The bulk ceramic $\mathrm{Y}_{2} \mathrm{O}_{3}: \mathrm{Er}^{3+} 1 \mathrm{~mol} \%$ was achieved by sintering the corresponding pressed powder disk (made of nanocrystals $\mathrm{Y}_{2} \mathrm{O}_{3}: \mathrm{Er}^{3+} 1 \mathrm{~mol} \%$ ) in a tubular furnace at $1300^{\circ} \mathrm{C}$ for $24 \mathrm{~h}$ in air. Further, the powders were pressed to form smooth and flat disks to be utilized for spectral studies by irradiation with a focused $976 \mathrm{~nm}$ diode laser (Hi-Tech Optoelectronics Co. Ltd, Beijing) at an output of $400 \mathrm{~mW}$. The focus area on the disk sample was measured to be about 1 $\mathrm{mm}^{2}$, resulting in a power density of about $40 \mathrm{~W} / \mathrm{cm}^{2}$. The emitted UCL was collected by a lens-coupled monochromator (Zolix Instruments Co. Ltd, Beijing) of 2-nm spectral resolution with an attached photomultiplier tube (Hamamatsu R928). All spectral measurements were performed at room temperature and preserving the same geometry for the UCL recording. X-ray diffraction patterns evidenced that the prepared powders were about $60 \mathrm{~nm}$ in diameter and there was no crystal structure changes for all these oxide nanocrystals via doping further with $\mathrm{Li}^{+}$ ions. The morphology of these rare-earth-doped nanocrystals are similar to that in our previous reports (Chen et al., 2008b).

\section{Results}

Figures 1a-c present the green UCL from $\mathrm{Y}_{2} \mathrm{O}_{3}$ and $\mathrm{Gd}_{2} \mathrm{O}_{3}$ nanocrystals doped with $1 \mathrm{~mol} \% \mathrm{Er}^{3+}$ ions and codoped with various $\mathrm{Li}^{+}$ions and from $\mathrm{ZnO}$ nanocrystals doped with $2 \mathrm{~mol} \% \mathrm{Er}^{3+}$ ions and codoped with various $\mathrm{Li}^{+}$ions under $976 \mathrm{~nm}$ diode laser excitation of about $40 \mathrm{~W} / \mathrm{cm}^{2}$. These emissions were identified to arise from the intra- $4 \mathrm{f}$ electronic transition ${ }^{2} \mathrm{H}_{11 / 2} /{ }^{4} \mathrm{~S}_{3 / 2} \rightarrow{ }^{4} \mathrm{I}_{15 / 2}$ of the $\mathrm{Er}^{3+}$ ions. As shown in these figures, codoping with $\mathrm{Li}^{+}$ions can remarkably enhance the green UCL in all these oxide nanocrystals. The green UCL are enhanced up to about 70, 33 and 35 times in $\mathrm{Y}_{2} \mathrm{O}_{3}, \mathrm{Gd}_{2} \mathrm{O}_{3}$ and $\mathrm{ZnO}$ nanocrystals when codoped with $\mathrm{Li}^{+}$ions of 5,5 and $2 \mathrm{~mol} \%$, respectively. The intensity of green UCL in nanocrytals of $\mathrm{Y}_{2} \mathrm{O}_{3}$ codoped with 5 $\mathrm{mol} \% \mathrm{Li}^{+}$ions can even reach one third of the one from the bulk counterpart (Fig. 1d), which means that such enhancement strategy enables UC nanocrystals to radiate like bulk materials. It is worthwhile to point out that ever since the first report by F. Auzel in the 1960s on UC enhancement through $\mathrm{Yb}^{3+}$ sensitization (Auzel, 2004), there have been limited strategies to increase the UCL by orders of magnitude. The significant UCL enhancements in various oxide nanocrystals illustrate well the general validity of the proposed strategy for different oxide host lattice.

Among rare-earth ions, the activators of $\mathrm{Tm}^{3+}, \mathrm{Er}^{3+}$ and $\mathrm{Ho}^{3+}$ ions sensitized by $\mathrm{Yb}^{3+}$ ions have been reported to be the most efficient UC systems in the literature (Auzel, 2004; Chen et al., 2014). Hence, we select them here as a model to demonstrate the general validity of the proposed strategy for the category of rare-earth ions. Figure 2 contrasts the UCL spectra of (a) single blue $\left({ }^{1} \mathrm{G}_{4} \rightarrow{ }^{3} \mathrm{H}_{6}\right)$ of $\mathrm{Tm}^{3+}$ ions in nanocrystals $\mathrm{Y}_{2} \mathrm{O}_{3}: \mathrm{Yb}^{3+} / \mathrm{Tm}^{3+}$ tridoped without and with $\mathrm{Li}^{+}$ions, (b) single green $\left({ }^{5} \mathrm{~S}_{2} /{ }^{5} \mathrm{~F}_{4} \rightarrow{ }^{5} \mathrm{I}_{8}\right)$ of $\mathrm{Ho}^{3+}$ ions in nanocrystals $\mathrm{Y}_{2} \mathrm{O}_{3}: \mathrm{Yb}^{3+} / \mathrm{Ho}^{3+}$ tridoped without and with $\mathrm{Li}^{+}$ions and (c) single red $\left({ }^{4} \mathrm{~F}_{9 / 2} \rightarrow{ }^{4} \mathrm{I}_{5 / 2}\right)$ of $\mathrm{Er}^{3+}$ ions in nanocrystals $\mathrm{Y}_{2} \mathrm{O}_{3}: \mathrm{Yb}^{3+} / \mathrm{Er}^{3+}$ tridoped without and with $\mathrm{Li}^{+}$ions. As expected, magnificent fluorescence increases (by one order of magnitude) were observed for all these types of rare-earth ions via tridoping with $\mathrm{Li}^{+}$ions. It should be noted that these achieved highly luminescent single-band UCL are of interest for background-free multicolor imaging and for simultaneous parallel quantitative analysis of multiple biological species. These achieved significant UCL enhancements in diverse rare-earth ions (codoping and tridoping) illustrate well the general validity of the proposed strategy for the class of rare-earth ions.

\section{Discussion}

Mechanisms for the UCL enhancement in $\mathrm{Er}^{3+}$-doped oxide nanocrystal $\left(\mathrm{Y}_{2} \mathrm{O}_{3}, \mathrm{Gd}_{2} \mathrm{O}_{3}\right.$ and $\left.\mathrm{ZnO}\right)$, as discussed in our previous report (Chen et al., 2008a), arise from the fact that the codoping of $\mathrm{Li}^{+}$ions can tailor the local crystal filed around the $\mathrm{Er}^{3+}$ ions. The tailored local crystal field will interact with $\mathrm{Er}^{3+}$ ion, slightly modify its wave functions and eventually alter the radiation parameters of the intermediate ${ }^{4} \mathrm{I}_{11 / 2}$ state and lead the UCL to increase by orders of magnitude. The same enhancement mechanism is expected for all these $\mathrm{Er}^{3+}$-doped oxide nanocrystals due to the fact that $\mathrm{Li}^{+}$ions have similar effects on the nanocrystal size, lattice structure, intensity ratio of the green to red UC emission and enhancement outcomes. Else, mechanisms for UCL enhancement in $\mathrm{Yb}^{3+} / \mathrm{Tm}^{3+}, \mathrm{Yb}^{3+} / \mathrm{Ho}^{3+}$ and $\mathrm{Yb}^{3+} / \mathrm{Er}^{3+}$ ions, may arise from the fact that the tridoping with $\mathrm{Li}^{+}$ions can tailor both the lifetime of the excited ${ }^{2} \mathrm{~F}_{5 / 2}$ state in $\mathrm{Yb}^{3+}$ ions and the lifetime of the intermediate states in $\mathrm{Tm}^{3+}, \mathrm{Ho}^{3+}$ and $\mathrm{Er}^{3+}$ ions. This is because that the sensitization of $\mathrm{Yb}^{3+}$ ions and the tailoring lifetime of rare-earth ions are two independent enhancement mechanisms for the UCL output (Chen et al., 2008b). 


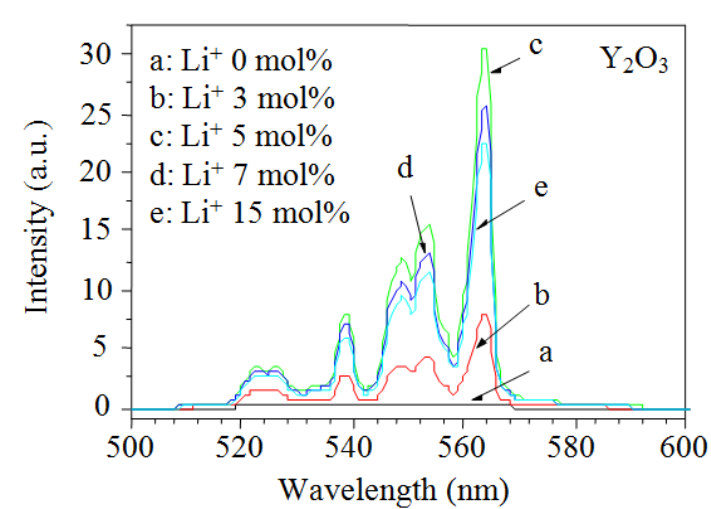

(a)

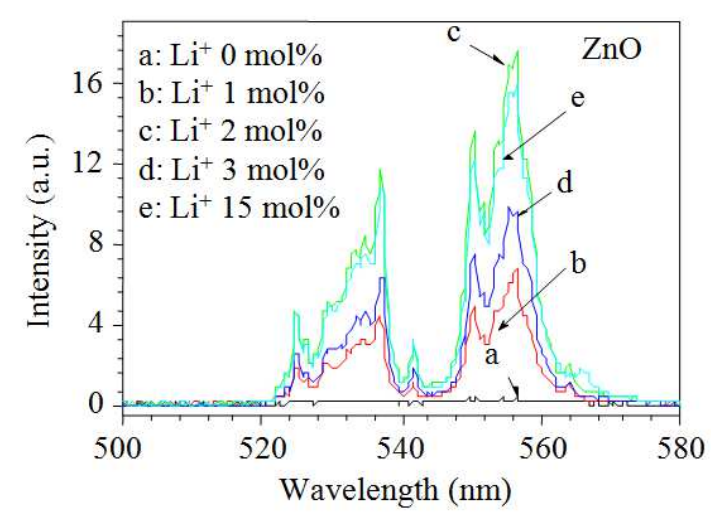

(c)

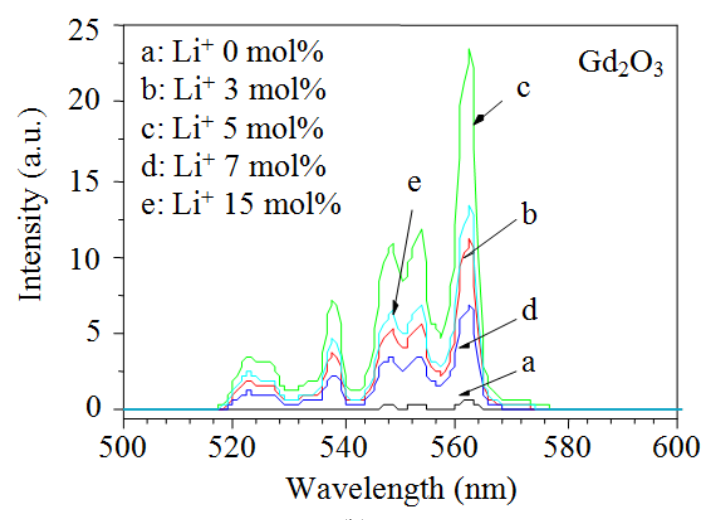

(b)

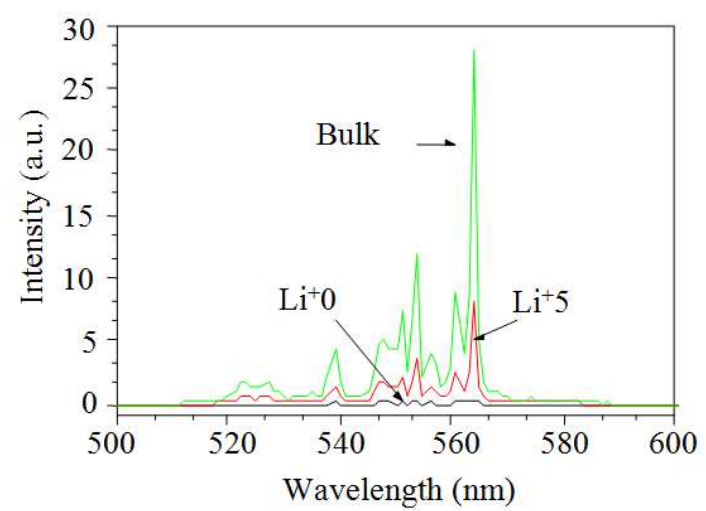

(d)

Fig. 1. Measured UCL of (a) $\mathrm{Y}_{2} \mathrm{O}_{3}: \mathrm{Er}^{3+} 1 \mathrm{~mol} \%$ nanocrystals, (b) $\mathrm{Gd}_{2} \mathrm{O}_{3}: \mathrm{Er}^{3+} 1 \mathrm{~mol} \%$ nanocrystals, (c) $\mathrm{ZnO}^{2} \mathrm{Er}^{3+} 2 \mathrm{~mol} \%$ nanocrystals codoped with various $\mathrm{Li}^{+}$ions under $976 \mathrm{~nm}$ diode laser excitation of $40 \mathrm{~W} / \mathrm{cm}^{2}$; (d) Constrasted UC spectra of nanocrytals and bulk $\mathrm{Y}_{2} \mathrm{O}_{3}: \mathrm{Er}^{3+} 1 \mathrm{~mol} \%$, as well as nanocrytals $\mathrm{Y}_{2} \mathrm{O}_{3}$ doped further with $5 \mathrm{~mol} \% \mathrm{Li}^{+}$ions

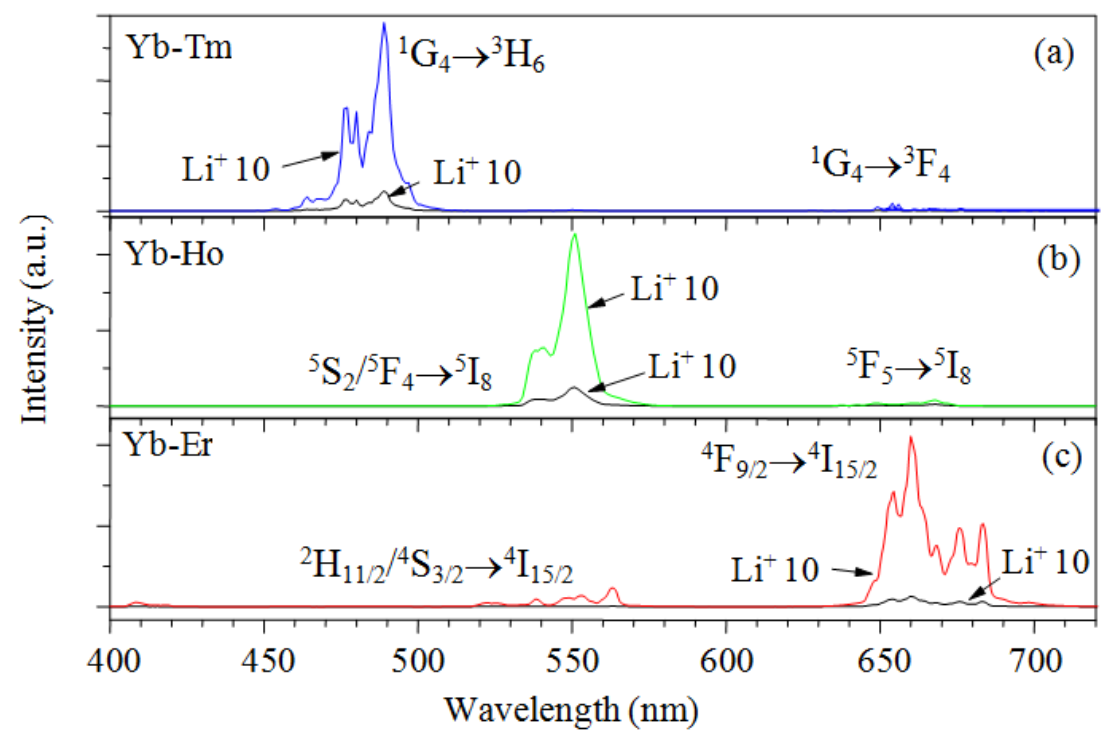

Fig. 2. Contrasted UCL spectra of the (a) single blue in nanocrystals $\mathrm{Y}_{2} \mathrm{O}_{3}$ doped with $3 \mathrm{~mol} \% \mathrm{Yb}^{3+}, 0.2 \mathrm{~mol}^{\circ} \mathrm{Tm}^{3+}$ ions and nanocrytals $\mathrm{Y}_{2} \mathrm{O}_{3}$ doped further with $15 \mathrm{~mol} \% \mathrm{Li}^{+}$ions, (b) single green in nanocrystals $\mathrm{Y}_{2} \mathrm{O}_{3}$ doped with $2 \mathrm{~mol}_{0} \mathrm{Yb}^{3+}, 1$ mol\% $\mathrm{Ho}^{3+}$ ions and nanocrytals $\mathrm{Y}_{2} \mathrm{O}_{3}$ doped further with $10 \mathrm{~mol} \% \mathrm{Li}^{+}$ions; and (c) single red in nanocrystals $\mathrm{Y}_{2} \mathrm{O}_{3}$ doped with $10 \mathrm{~mol} \% \mathrm{Yb}^{3+}, 1 \mathrm{~mol} \% \mathrm{Er}^{3+}$ ions and nanocrytals $\mathrm{Y}_{2} \mathrm{O}_{3}$ doped further with $10 \mathrm{~mol} \% \mathrm{Li}^{+}$ions 

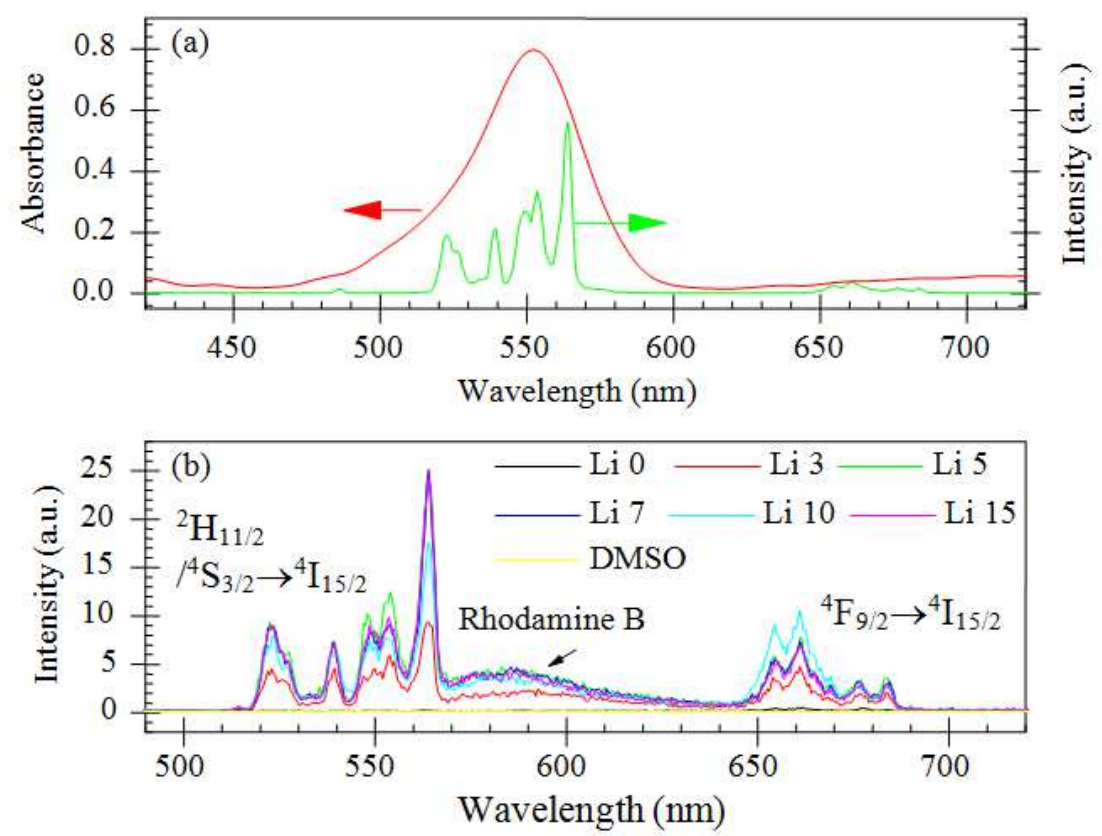

Fig. 3. (a) The absorpbance of Rhodamine $\mathrm{B}$ and the UCL spectrum from colloidal $\mathrm{Y}_{2} \mathrm{O}_{3}: \mathrm{Er}^{3+} 1 \mathrm{~mol} \%$ nanocrystals in DMSO solution with different scales marked by the arrows in the figure; (b) visible fluorescence of DMSO solutions containing Rodamine $\mathrm{B}$ and $\mathrm{Y}_{2} \mathrm{O}_{3}: \mathrm{Er}^{3+} 1 \mathrm{~mol} \%$ nanocrystals doped with various $\mathrm{Li}^{+}$ions under diode laser excitation of $976 \mathrm{~nm}$

As a proof-of-principle, a model PDT experiment was implemented by pumping $\mathrm{Y}_{2} \mathrm{O}_{3}: \mathrm{Er}^{3+}$ nanocrystals with $976 \mathrm{~nm}$ diode laser for UC-mediated resonant (Fig. 3a) excitation of organic Rhodamine B molecules dissolved in a DMSO solution. The fluorescence of the organic dye-here acting as ad hoc photosensitizer-can reflect the output of ${ }^{1} \mathrm{O}_{2}$, which has the direct task to destroy the tumor cells. The three peaks in Fig. $3 b$ centered around 560, 590 and $660 \mathrm{~nm}$ can easily be assigned to the green UC emission, the Rhodamine B fluorescence and the red UC emission, respectively. The fluorescence of Rhodamine $\mathrm{B}$ in DMSO solutions containing $\mathrm{Y}_{2} \mathrm{O}_{3}$ nanocrystals doped only with $\mathrm{Er}^{3+}$ ions is too weak to be displayed. In contrast, the fluorescence of Rhodamine $\mathrm{B}$ in solution with $\mathrm{Y}_{2} \mathrm{O}_{3}: \mathrm{Er}^{3+} 1 \mathrm{~mol} \%$ nanocrystals codoped with $\mathrm{Li}^{+}$ions can be clearly observed and their intensities follow the same tendency as that of Fig. 1a. As demonstrated, the significant fluorescence increase in UC nanocrystals can expectedly result in a great enhancement of the fluorescent signal in organic dyes, these being potential photosensitizers in PDT and thereby increasing the output of ${ }^{1} \mathrm{O}_{2}$.

\section{Conclusion}

In summary, we have demonstrated a general strategy to increase the UCL by orders of magnitude via nonluminescent $\mathrm{Li}^{+}$ions doping in rare-earth-ion-doped oxide nanocrystals, such as $\mathrm{Y}_{2} \mathrm{O}_{3}, \mathrm{Gd}_{2} \mathrm{O}_{3}$ and $\mathrm{ZnO}$ doped with $\mathrm{Er}^{3+}, \mathrm{Yb}^{3+} / \mathrm{Er}^{3+}, \mathrm{Yb}^{3+} / \mathrm{Ho}^{3+}$ and $\mathrm{Yb}^{3+} / \mathrm{Tm}^{3+}$. The achieved UCL, for example, in $\mathrm{Li}^{+}$-codoped $\mathrm{Y}_{2} \mathrm{O}_{3}: \mathrm{Er}^{3+}$ nanocrytals can even be comparable to that of the bulk counterpart. Such enhancement mainly arises from the modification of rare-earth ions' local environment by $\mathrm{Li}^{+}$ ions doping. A proof-of-principle PDT experiment targeting treatment of deep tumors suggests the advantage of significantly increased UCL for various photonic and biomedical applications.

\section{Acknowledgement}

We thank Mr. Deyang Li for editing the format of this manuscript.

\section{Funding Information}

This work is supported by the Fundamental Research Funds for the Central Universities, China (AUGA 5710052614 and 8880100415 ).

\section{Author's Contributions}

Guanying Chen: Developed the idea, performed the experiments, analyzed the data and wrote the manuscript.

Lei Xu: Performed some of the experiments.

\section{Ethics}

We would like to disclose that Dr. Guanying Chen is an Associate Editor for the American Journal of Engineering and Applied Sciences. 


\section{References}

Auzel, F., 2004. Upconversion and anti-stokes processes with $\mathrm{f}$ and $\mathrm{d}$ ions in solids. Chem. Rev., 104: 139-173. DOI: 10.1021/cr020357g

Bai, Y.F., K. Yang, Y.X. Wang, X.R. Zhang and Y.L. Song, 2008. Enhanced upconverted photoluminescence in $\mathrm{Er}^{3+}$ and $\mathrm{Yb}^{3+}$ codoped $\mathrm{ZnO}$ nanocrystals with and without $\mathrm{Li}^{+}$ions. Opt. Comm., 281: 5448-5452. DOI: 10.1016/j.optcom.2008.07.041

Chen, G.Y., H.C. Liu, G. Somesfalean, Y.Q. Sheng and H.J. Liang et al., 2008a. Enhancement of the upconversion radiation in $\mathrm{Y}_{2} \mathrm{O}_{3}: \mathrm{Er}^{3+}$ nanocrystals by codoping with $\mathrm{Li}^{+}$ions. Applied Phys. Lett., 92: 113114-113114. DOI: 10.1063/1.2901039

Chen, G.Y., H.C. Liu, H.J. Liang, G. Somesfalean and Z.G. Zhang, 2008b. Upconversion emission enhancement in $\mathrm{Yb}^{3+} / \mathrm{Er}^{3+}$-codoped $\mathrm{Y}_{2} \mathrm{O}_{3}$ nanocrystals by tridoping with $\mathrm{Li}^{+}$ions. J. Phys. Chem. C, 112: 12030-12036. DOI: $10.1021 / j p 804064 \mathrm{~g}$

Chen, G.Y., H.L. Qiu, P.N. Prasad and X. Chen, 2014. Upconversion nanoparticles: Design, nanochemistry and applications in theranostics. Chem. Rev., 114: 5161-5214. DOI: $10.1021 / \mathrm{cr} 400425 \mathrm{~h}$

Lim, S.F., R. Riehn, W.S. Ryu, N. Khanarian and C.K. Tung et al., 2006. In vivo and scanning electron microscopy imaging of upconverting nanophosphors in Caenorhabditis elegans. Nano Lett., 6: 169-171. DOI: $10.1021 / \mathrm{nl} 0519175$

Liu, F., E. Ma, D.Q. Chen, Y.L. Yu and Y.S. Wang, 2004. Tunable red-green upconversion luminescence in novel transparent glass ceramics containing Er: $\mathrm{NaYF}_{4}$ nanocrystals. J. Phys. Chem. B, 110: 20843-20846. DOI: 10.1021/jp063145m
Shalav, A., B.S. Richards, T. Trupke, K. Kömpe and H.U. Güdel, 2005. Application of $\mathrm{NaYF}_{4}: \mathrm{Er}^{3+}$ upconverting phosphors for enhanced near-infrared silicon solar cell response. Applied Phys. Lett., 86: 013505-013505. DOI: 10.1063/1.1844592

Sivakumar, S., F.C.J.M. van Veggel and P.S. May, 2007. Near-Infrared (NIR) to red and green up-conversion emission from silica sol-gel thin films made with $\mathrm{La}_{0.45} \mathrm{Yb}_{0.50} \mathrm{Er}_{0.05} \mathrm{~F}_{3}$ nanoparticles, hetero-loopingenhanced energy transfer (Hetero-LEET): A new up-conversion process. J. Am. Chem. Soc., 129: 620-625. DOI: 10.1021/JA065378x

Suyver, J.F., A. Aebischer, D. Biner, P. Gerner and J. Grimm et al., 2005. Novel materials doped with trivalent lanthanides and transition metal ions showing near-infrared to visible photon upconversion. Opt. Mater., 27: 1111-1130. DOI: 10.1016/j.optmat.2004.10.021

Vetrone, F., J.C. Boyer, J.A. Capobianco, A. Speghini and M. Bettinelli, 2003. Luminescence spectroscopy and near-infrared to visible upconversion of nanocrystalline $\mathrm{Gd}_{3} \mathrm{Ga}_{5} \mathrm{O}_{12}: \mathrm{Er}^{3+}$. J. Phys. Chem. B, 107: 10747-10752. DOI: 10.1021/jp030434r

Wang, L.Y. and Y.D. Li, 2006. Green upconversion nanocrystals for DNA detection. Chem. Commun., 24: 2557-2559. DOI: 10.1039/b604871d

Weber, M., 1967. Probabilities for radiative and nonradiative decay of $\mathrm{Er}^{3+}$ in $\mathrm{LaF}_{3}$. Phys. Rev., 157: 262-262. DOI: 10.1103/PhysRev.157.262 